\title{
EFFECTS OF ISOBARIC BUPIVACAINE IN ENDOSCOPIC UROLOGICAL SURGERIES UNDER SPINAL ANAETHESIA
}

\author{
Hussain $\mathrm{MD}^{1}$, Mallick $\mathrm{MT}^{2}$
}

\begin{abstract}
Introduction: Isobaric bupivacaine is not routinely practiced as a subarachnoid block, though it may be used as an alternative to traditional hyperbaric solution with less complications and a good operative condition in endoscopic urologic surgery.

Objective: This prospective randomized study was conducted over a period of 18 months to evaluate the effects of isobaric bupivacaine with low dose fentanyl in endoscopic urologic surgeries under spinal anaesthesia.
\end{abstract}

Methods: Two equally sized groups $(n=60)$ of male patients were randomly selected and studied for routine endo-urological surgeries under subarachnoid block. One group received $0.5 \%$ hyperbaric bupivacaine (HBF) and the other group received $0.5 \%$ isobaric bupivacaine (IBF). In both groups bupivacaine was mixed with low dose fentanyl (10 microgram) and $1 \mathrm{ml}$ distilled water. Non-invasive blood pressure, heart rate, $\mathrm{SpO}_{2}$, levels of sensory and motor blockade were recorded frequently. Complications of intrathecal block (if developed) were also recorded and treated.

Results: The mean operation time was $49.9 \pm 9.55$ and 50.10.10 \pm 7.98 minutes in HBF and IBF groups respectively and the difference was not statistically significant $(p>0.05)$. The mean time to request for first analgesic was $402.50 \pm 37.21$ and $288.90 \pm 25.22$ minutes in HBF and IBF groups respectively and the difference was statistically significant $(p<0.001)$. There was no difference in the level of sensory block and total amount of fluid infused $(p>0.05)$. Base line heart rate and blood pressure of the two studied groups were similar. After the subarachnoid block blood pressure reduced significantly in both the groups $(p<0.001)$ but remained within the acceptable level for the surgery. No significant differences in complications like shivering, nausea, vomiting, hypotension, bradycardia were observed in the groups.

Conclusion: Intrathecal isobaric bupivacaine with low dose fentanyl may be used as an alternative to traditional hyperbaric bupivacaine for endoscopic urologic surgeries with less side effects related to intrathecal opioid.
Keywords: Isobaric bupivacaine, subarachnoid block, hyperbaric

\section{Introduction}

The efficacy and use of local anaesthetics is increasing. This is a result of advances in drugs, equipment and the anatomical approaches to nerve block together with a greater understanding of the relationships between the doses, concentrations and subsequent effects of local anaesthetic agents employed. Many local anaesthetic techniques administered for the purpose of operative surgery may provide excellent analgesia in the early postoperative period. Sub-arachnoid analgesia rarely lasts more than 3-4 hours with the drugs currently available and is therefore of limited use for postoperative analgesia ${ }^{1}$.

The administration of local anaesthetics, opioids or a combination neuroaxially (sub-arachnoid or epidural) is an excellent technique for managing postoperative pain following abdominal, pelvic or orthopaedic procedures on the lower extremities. Patients often have better presentation of pulmonary function, are able to ambulate early and benefit from physical therapy with lower risk for postoperative venous thrmbosis ${ }^{2}$.

Spinal anaesthesia with a $\mathrm{T}_{10}\left(10^{\text {th }}\right.$ Thoracic vertebra $)$ sensory level provides excellent anaesthesia and good operating condition for cysto-endoscopic surgery ${ }^{3,4}$. The classic isobaric spinal anaesthetic provides a block that is dense in lower thoracic, lumber and sacral areas and is ideally suited to perineal, urologic and lower extremity surgery. Because the block does not extend into the upper thoracic level, it results in a partial sympathetic block with minimum haemodynamic changes ${ }^{5}$.

Spinal opioid improve the quality and duration of analgesia but at the risk of specific side effects. By adding fentanyl to local anaesthetic solution, the requirement of local anaesthetic solution can be reduced. Fentanyl when administered intrathecally has no blocking effect on autonomic or motor fibres ${ }^{6,7}$. Common side effects are itching, nausea, vomiting, urinary

1. Lt Col Muhammad Delwar Hussain MBBS, FCPS, Graded Specialist in Anaesthesiology, CMH Dhaka, e-mail: drdelwarhussain@yahoo.com; 2. Lt Col Md Torab Mallick MBBS, FCPS, Graded Specialist in Anaesthesiology, CMH Jessore. 
retention, sedation and ileus ${ }^{8}$. A large intravenous preload is rarely necessary or advisable as it may increase the risk of TURP syndrome ${ }^{9}$. Study comparing the effect of intrathecal isobaric and hyperbaric bupivacaine with fentanyl for endoscopic urological surgeries are available ${ }^{7,10}$.

The aim of this study was to compare and evaluate the onset of action, duration of analgesia, quality of block, effects on haemodynamic status and other complications on adding small dose of fentanyl with isobaric and hyperbaric bupivacaine intrathecally in Bangladeshi environment.

\section{Materials and Methods}

This prospective study was carried out in the Department of Anaesthesia and Intensive Care, Combined Military Hospital (CMH) Dhaka during the period from September 2009 to February 2011. Prior permission was taken from the hospital authority explaining the purpose and the procedure of the study. Informed consent was also taken from each study subject.

Total 120 male patients of grades ASA I and ASA II (American Society of Anaesthesiologist Classification) were randomly selected and studied for routine endourological procedures under sub-arachnoid block (SAB). Those patients were allocated by card sampling method into two groups each having sixty patients. One group received $2 \mathrm{ml}$ of $0.5 \%$ hyperbaric bupivacaine and 10 microgram of fentanyl in $1 \mathrm{ml}$ of distilled water (Hyperbaric Bupivacaine group - HBF) and the other group received $2 \mathrm{ml}$ of $0.5 \%$ plain isobaric bupivacaine and 10 microgram fentanyl in $1 \mathrm{ml}$ of distilled water (Isobaric Bupivacaine group- IBF). Preexisting fluid deficit was corrected prior to anaesthesia by giving fluid at the rate of $1.5 \mathrm{ml} / \mathrm{kg}$ for every hour of fasting.

The patients fasted as required for general anaesthesia. No pre-medication was given; but all patients were reassured and the anaesthetic procedure was explained on the day before the operation. Intravenous access was established in all patients in the operating room. Base line heart rate and blood pressure (non-invasive) were obtained. Each patient received an intravenous fluid load of $300 \mathrm{ml}$ of Ringer lactate solution over 15 minutes and they also received $40 \%$ oxygen by face mask throughout the anaesthetic period.

Every patient received a subarachnoid block in the sitting position at the L2-3 or L3-4 level via $25 \mathrm{G}$ Quincke Babcock needle. The anaesthetic agents were injected intrathecally over 20 seconds after confirming the free flow of cerebrospinal fluid coming through the needle with the bevels facing laterally. The patients were then turned to the supine position leaving a sterile dressing over the lumber puncture site. During the first 30 minutes after spinal anaesthesia, the patients were assessed as follows: non-invasive blood pressure, heart rate (continuous lead II ECG), $\mathrm{SpO}_{2}$, temperature, level of sensory block to pin prick and degree of motor blockade on the modified Bromage Scale and recorded at just after block, after 3 minutes, after 10 minutes and thereafter every 5 minutes interval. Each patient was assessed and recorded regarding shivering, nausea, vomiting, hypotension, bradycardia at intervals till the surgical procedure was completed and on arrival at recovery room. Any reduction of systolic arterial blood pressure of more than $30 \%$ of the base line was promptly treated with $5 \mathrm{mg}$ i/v boluses of ephedrine. Amount of ephedrine and total fluid infused till the end of surgery were also recorded.

After reassessing and stabilizing the vital parameters in the recovery area the patients were sent to the postoperative ward, where they were assessed immediately and in every half an hour interval. The time taken to request for first analgesia as well as the degree of sedation, respiratory depression, pruritus, nausea, vomiting were recorded on a preformed data sheet during the first 24 hours post-operatively.

The observations of present study were processed and analysed by SPSS software (version 17) as required. All results are expressed as mean $\pm \mathrm{SD}$ or in frequencies as applicable. A p value $<0.05$ was considered to be statistically significant.

\section{Results}

There were no significant differences in age, body weight, height, ASA grading and in clinical data of two groups (Table I). The mean operation time of the present study were $49.96+$ 9.55 and $50.10+7.98$ minutes and there was no significant differences $(\mathrm{p}>0.05)$. The time to request for first analgesic were $402.50 \pm 37.21$ and $288.90 \pm 25.22$ minutes and was highly significant $(\mathrm{p}<0.001)$ in group HBF (Table II). Various data and their analysis are shown in the following tables.

Table-I: Demographic features

\begin{tabular}{|c|c|c|c|}
\hline Parameters & $\begin{array}{c}\text { Group-HBF } \\
(n=60)\end{array}$ & $\begin{array}{c}\text { Group-IBF } \\
(n=60)\end{array}$ & p value \\
\hline Age (in years) & $52.33 \pm 6.05$ & $50.93 \pm 4.06$ & \multirow{5}{*}{$>0.05$} \\
\hline Weight (in Kg) & $55.20 \pm 4.22$ & $57.46 \pm 3.25$ & \\
\hline Height (in cm) & 165.30 & $166.13 \pm 4.94$ & \\
\hline $\begin{array}{l}\text { ASA physical status } \\
\text { I } \mathrm{f}(\%) \\
\text { II } \quad \mathrm{f}(\%)\end{array}$ & $\begin{array}{l}50(83.33) \\
10(16.66)\end{array}$ & $\begin{array}{l}48(80) \\
12(20)\end{array}$ & \\
\hline $\begin{array}{l}\text { TURP/TURB/ } \\
\text { URS (frequency) }\end{array}$ & $34 / 16 / 10$ & $36 / 11 / 13$ & \\
\hline
\end{tabular}


Table-II: Operative Data

\begin{tabular}{|l|c|c|l|}
\hline Parameters & $\begin{array}{l}\text { Group-HBF } \\
(\mathbf{n = 6 0 )}\end{array}$ & $\begin{array}{c}\text { Group-IBF } \\
(\mathbf{n = 6 0 )}\end{array}$ & p value \\
\hline $\begin{array}{l}\text { Duration of operation } \\
\text { (in minutes) }\end{array}$ & $49.96 \pm 9.55$ & $50.10 \pm 7.98$ & $>0.05$ \\
\hline $\begin{array}{l}\text { Duration of analgesia } \\
\text { (in minutes) }\end{array}$ & $402.50 \pm 37.21$ & $288.90 \pm 25.22$ & $<0.001$ \\
\hline
\end{tabular}

Table-III: Data related to SAB

\begin{tabular}{|c|c|c|c|}
\hline Parameters & $\begin{array}{c}\text { Group-HBF } \\
(\mathrm{n}=60)\end{array}$ & $\begin{array}{c}\text { Group-IBF } \\
(\mathbf{n}=60)\end{array}$ & p value \\
\hline $\begin{array}{l}\text { Total fluid infused } \\
\text { (in ml) }\end{array}$ & $715.00 \pm 128.75$ & $681.50 \pm 125.70$ & $>0.05$ \\
\hline $\begin{array}{cc}\text { Space used for SAB } \\
\mathrm{L}_{2-3} \quad \mathrm{f}(\%) \\
\mathrm{L}_{3-4} \text { f }(\%)\end{array}$ & $\begin{array}{l}18(30) \\
42(70)\end{array}$ & $\begin{array}{l}20(33.33) \\
40(66.66)\end{array}$ & $\begin{array}{l}>0.05 \\
>0.05\end{array}$ \\
\hline $\begin{array}{cc}\text { Level of sensory } \\
\text { block at } 30 \mathrm{~mm} \\
\mathrm{~T}_{4} & \mathrm{f}(\%) \\
\mathrm{T}_{8} & \mathrm{f}(\%) \\
\mathrm{T}_{10} & \mathrm{f}(\%)\end{array}$ & $\begin{array}{l}00 \\
46(76.66) \\
14(23.33)\end{array}$ & $\begin{array}{l}02(3.33) \\
42(70) \\
16(26.66)\end{array}$ & $\begin{array}{l}<0.001 \\
>0.05 \\
>0.05\end{array}$ \\
\hline
\end{tabular}

Table-IV: Changes of heart rate at different time interval

\begin{tabular}{|l|l|l|l|}
\hline Time & $\begin{array}{c}\text { Group-HBF } \\
(\mathbf{n}=\mathbf{6 0})\end{array}$ & $\begin{array}{c}\text { Group-IBF } \\
(\mathbf{n}=\mathbf{6 0})\end{array}$ & p value \\
\hline Base line & $79.00 \pm 9.50$ & $76.16 \pm 9.18$ & \\
\hline Just after block & $81.33 \pm 11.85$ & $77.66 \pm 10.59$ \\
\hline 3 minutes after block & $80.16 \pm 9.25$ & $76.46 \pm 10.50$ & \multirow{2}{*}{$>0.05$} \\
\hline 10 minutes after block & $78.50 \pm 11.25$ & $75.30 \pm 10.25$ & \\
\hline 30 minutes after block & $78.63 \pm 10.02$ & $74.53 \pm 8.99$ & \\
\hline Immediate post op period & $75.30 \pm 8.98$ & $72.53 \pm 7.11$ & \\
\hline 04 hr after block & $76.90 \pm 8.16$ & $81.53 \pm 6.85$ & \\
\hline
\end{tabular}

Table-V: Changes of systolic blood pressure at different time interval

\begin{tabular}{|c|c|c|c|}
\hline Time & $\begin{array}{c}\text { Group-HBF } \\
(n=60)\end{array}$ & $\begin{array}{c}\text { Group-IBF } \\
(\mathrm{n}=60)\end{array}$ & p value \\
\hline Base line & $145.36+12.89$ & $140.83+12.25$ & \multirow{7}{*}{$<0.001$} \\
\hline Just after block & $131.86+15.32$ & $128.63+11.36$ & \\
\hline 3 minutes after block & $126.33+13.2$ & $125.33+9.86$ & \\
\hline 10 minutes after block & $116.43+15.15$ & $119.86+11.95$ & \\
\hline 30 minutes after block & $118.26+12.82$ & $114.93+13.65$ & \\
\hline Immediate post op period & $123.56+14.51$ & $121.90+12.85$ & \\
\hline $04 \mathrm{hr}$ after block & $130.76+8.23$ & $119.40+8.82$ & \\
\hline
\end{tabular}

Table-VI: Changes of diastolic blood pressure in different time

\begin{tabular}{|l|c|c|c|}
\hline Time & $\begin{array}{c}\text { Group-HBF } \\
(\mathbf{n}=\mathbf{6 0})\end{array}$ & $\begin{array}{c}\text { Group-IBF } \\
(\mathbf{n}=\mathbf{6 0})\end{array}$ & p value \\
\hline Base line & $76.90 \pm 11.25$ & $78.80 \pm 8.76$ & \\
\hline Just after block & $73.83 \pm 7.63$ & $74.00 \pm 9.86$ \\
\hline 3 minutes after block & $70.83 \pm 7.90$ & $68.83 \pm 7.90$ & \multirow{2}{*}{$<0.001$} \\
\hline 10 minutes after block & $64.03 \pm 5.02$ & $60.26 \pm 6.20$ & \\
\hline 30 minutes after block & $62.60 \pm 6.95$ & $64.40 \pm 6.33$ \\
\hline Immediate post op period & $69.33 \pm 6.27$ & $68.46 \pm 7.56$ & \\
\cline { 1 - 3 } $04 \mathrm{hr}$ after block & $71.66 \pm 6.04$ & $70.70 \pm 6.04$ & \\
\hline
\end{tabular}

Table-VII: Distribution of different types of peroperative complications

\begin{tabular}{|l|l|l|l|}
\hline Nature of complications & $\begin{array}{l}\text { Group-HBF } \\
(\mathbf{n = 6 0 )} \\
\text { f (\%) }\end{array}$ & $\begin{array}{l}\text { Group-IBF } \\
\text { (n=60) } \\
\text { f (\%) }\end{array}$ & p value \\
\hline Nausea and/or vomiting & $11(18.33)$ & $11(18.33)$ & \\
\hline Bradycardia & 00 & $02(03.33)$ & \multirow{2}{*}{$>0.05$} \\
\hline Respiratory depression & $01(01.67)$ & $01(01.67)$ \\
\hline Sedation & $03(05.00)$ & $02(03.33)$ & \\
\hline Pruritus & $02(03.33)$ & $03(05.00)$ & \\
\hline
\end{tabular}

\section{Discussion}

In the present study $2 \mathrm{ml}$ of $0.5 \%$ plain isobraic and hyperbaric bupivacaine with $10 \mathrm{~g}$ fentanyl were used for induction of subarachnoid block. The blocks were performed in sitting position. The final heights of blocks were assessed by pin prick, 30 minutes after block. Because bupivacaine fixes up at that time and no further progress of block occurs. Central neuroaxial block with a $\mathrm{T}_{10}$ sensory level produces excellent anaesthesia and good operating conditions for TURP ${ }^{11}$. Baricity of anaesthetic solution has been shown to affect level of neural blockade following spinal anaesthesia. Migration of local anaesthetic cephalad in CSF depends on its specific gravity relative to CSF with a head down position, a hyperbaric solution spreads cephalad ${ }^{12}$. An isobaric solution tends to remain at the level of injection. Hyperbaric solution tends move to the most dependent area of the spine with normal spinal anatomy, the apex of the thoracolumber curvature is $\mathrm{T}_{4}$ in the supine position. This should limit a hyperbaric solution to produce a level of anaesthesia at or below $\mathrm{T}_{4}{ }^{13}$.

In the isobaric bupivacaine group in this study sensory level reached at $\mathrm{T}_{4}$ for two patients but not in hyperbaric group. This may be due to rapidity of injection of drug into the intrathecal space. In most of the patients level of sensory block was at $\mathrm{T}_{8}$ dermatome. Only eight in isobaric group and seven in hyperbaric group patient exhibited the predicted level of block at $\mathrm{T}_{10}$. This result is consistent with the study conducted by Abdelmomen et $\mathrm{al}^{14}$. The classic isobaric spinal anaesthetic provides a block that is dense in lower thoracic, lumber and sacral areas and is ideally suited to perineal, urologic and lower extremity surgery. Because the block does not extend into the upper thoracic level it results in a partial sympathetic block with minimum haemodynamic changes $^{13}$.

In the present study the time to request first analgesic demand in the post operative period was significantly higher in hyperbaric group and this may be due to synergism between intrathecal opioids and local anaesthetics ${ }^{8}$. The cardiovascular effects of subarachnoid block are proportional to the height of block and result from denervation of the sympathetic outflow tracts. This produces dilatation of resistance and capacitance vessels and results in hypotension. The haemodynamic status of 
the two groups in the present study was similar. Two patients in plain isobaric bupivacaine group developed bradycardia and was treated with injection atropine 0.3 mg intravenously. There were no significant differences in systolic and diastolic pressure in both groups. These findings are correlated with the study of San et $\mathrm{al}^{15}$. Transurethral prostatic resection often opens extensive network of venous sinuses in the prostate and potentially allows systemic absorption of the irrigating fluid ${ }^{9}$. No such complications developed in this study. Sia used intrathecal opioid as an alternative anaesthetic for transurethral resection of prostate and concluded that there was a higher incidence of sedation, nausea and vomiting $^{16}$.

In this study $10 \mathrm{~g}$ of fentanyl with local anaesthetic solution was added into the intrathecal space and found no significant differences in side effects of intrathecal opioids like nausea, vomiting, itching and sedation or ventilatory depression. This is consistent with the study of Kararmaz et $\mathrm{al}^{17}$.

\section{Conclusion}

Intrathecal fentanyl along with local anaesthetic solution bupivacaine provides a very good anaesthesia for transurethral resection of prostate. Present study revealed that when $10 \mathrm{~g}$ of fentanyl is added to bupivacaine intrathecally, $10 \mathrm{mg}$ of isobaric bupivacaine is good enough for subarachnoid block in endoscopic urological surgery. Apart from this, patients who received $10 \mathrm{~g}$ of intrathecal fentanyl had fewer side effects related to intrathecal administration of opioid. This $10 \mathrm{mg}$ isobaric bupivacaine and $10 \mathrm{~g}$ fentanyl may be an alternative to traditional hyperbaric bupivacaine.

\section{References}

1. Lee A. Local Anaethetic Techniques.In: Aitkenhead AR,Rowbtham DJ, Smith G, editors. Text book of Anaesthesia. 4th ed. London:Churchill Livingstone; 2001.p.555-,75.
2 . Morgan GE ,Mikhael MS, Murray MJ. Clinical Anaesthesiology. 3rd ed. London: The Mc Graw-Hill Companies ; 2002.p.342-46.

3. Morgan GE ,Mikhael MS, Murray MJ. Clinical Anaesthesiology. 3rd ed. London: The Mc Graw-Hill Companies ; 2002.p.267,694-96.

4. Shewali S, Shrotey VR. Anaesthesiology GMC and Sir JJ group of Hospitals, Mumbai, India and Anaesthesiology GMC Nagpur India (Spons. S. Shewali): Spinal Analgesia with heavy and plain $0.5 \%$ Bupivacaine for prostate surgery. Abstract World Congress of pain. USA: 2002 August 22.p.201-205.

5. Yentis M, Hirsch N,Smith G.Transurethral Resection of Prostate (TURP);Anaesthesia and Intensive Care A-Z: An Encyclopaedia of Principles and Practice.4th ed. London: Churchill Livingstone; 2009.p. 502-541.

6. Harsoor SS, Vikram MS. Spinal anaesthesia with low dose bupivacaine with fentanyl for caesarean section. SAARC J Anaesth 2008; 1(2): 142-145.

7. Kim SY,Cho JE, Hong jy, Koo BN,Kim JM, Kill HK. Comparison of intrathecal fentanyl and sufentanyl in low dose dilute bupivacaine spinal anaesthesia for transurethral prostatectomy. Br J Anaesth 2099 Nov; 103(5): 750-4.

8. Bogra J, Arora N, Srivastava P. Synergistic effect of fentanyl and bupivacaine in spinal anaesthesia in caesarean section. BMC Anaesthesiol 2005; 5:5.

9. Harwary A, Mukhtar k, Sinclair A, Pearce I. Transurethral Resection of the Prostate Syndrome: Almost gone but not Forgotten. Journal of Endourology 2009 Dec; 23(12): 2013-20.

10. Sen H. Comparison of intrathecal hyperbaric and isobaric levobupivacaine in urological surgery. Minerva Anesthesiologica (internet) 2009 September: 75(9).

11. Portar M, McCormick B. Anaesthesia for transurethral resection of prostate.Update in Anaesthesia 2003 June;16(8):21-26.

12. Solakovic N. Comparison of haemodynamic effects of hyper and isobaric bupivacaine in spinal anaesthesia. Med Arh (internet) 2010; 64(1): 11-14.

13. Rofaeel A, Likker S, Fallah S, Goldszmidt, Carvalho J. Intrathecal plain vs hyperbaric bupivacaine for labour analgesia;efficacy and effects. Can J Anaesthesia 2007 Jan; 54(1):15-20.

14. Abdelmomen A. Low-dose hyperbaric bupivacaine injected at T12L1 provides adequqate anaesthesia with stable haemodynamics for elderly patients undergoing TURP.Egyptian Journal of Anaesthesia(internet) 2011 May

15. San BL. Use of hyperbaric versus isobaric bupivacaine for spinal anesthesia for caesarean section. ANZCA (internet) 2010 ASM

16. Sia AT, Chow MY, Koya CK, Chong JL. Intrathecal pethedine: an alternative anaesthetic for transurethral resection of prostate. Anaesthesia Intensive Care 1997 Dec; 25(6): 2013-20

17. Kararmaz A, Kaya S, Turhanoglu S, Ozyilmaz MA. Low dose bupivacaine-fentanyl spinal anaesthesia for transurethral prostatectomy. Anaesthesia 2003, 58: 526-530. 